\title{
Effects of Metal Types on Residual Stress in Electron-Beam Welding Joints with Sheet Metals
}

\author{
Takuya NAGAI, ${ }^{1) *}$ Ryu KASAI, ${ }^{1)}$ Kunika UENO, ${ }^{21}$ Masahito MOCHIZUKI' ${ }^{3)}$ and Tetsuo SUGA ${ }^{4)}$ \\ 1) Shinko Welding Service Co., Ltd. (Kobe Steel Group), 100-1 Miyamae, Fujisawa, Kanagawa, 251-8551 Japan. \\ 2) Tosei Electrobeam Co., Ltd., 651-6 Takane, Mizuho-machi, Nishitama-gun, Tokyo, 190-1203 Japan. \\ 3) Graduate School of Engineering, Osaka University, 2-1 Yamada-oka, Suita, Osaka, 565-0871 Japan. \\ 4) Joining and Welding Research Institute, Osaka University, 11-1 Mihogaoka, Ibaraki, Osaka, 567-0047 Japan.
}

(Received on May 30, 2014; accepted on September 11, 2014)

\begin{abstract}
The effect of metal types on the residual stresses has been researched through X-ray stress measurement for the electron-beam welding joints made of sheet metals with a thickness of approximately $10 \mathrm{~mm}$. The finite-element method (FEM) has also been used to analyze the experimental results and verify the residual stress characteristics. Consequently, it has been revealed that the residual stress near the weld toe in the longitudinal direction along the weld axis becomes tensile to a larger extent as the yield strength of the testing material is higher. By contrast, in the transverse direction, the residual stress close to the weld toe has been found to be compressive to a higher degree as the yield strength of the testing material is bigger. These correlations can be observed not only for ferritic and martensitic steel materials but also for other types of metals such as austenitic stainless steel of SUS304 and aluminum alloy of A5052.
\end{abstract}

KEY WORDS: electron beam weld; finite element method; residual stress; X-ray stress analysis; metal type.

\section{Introduction}

Residual stresses in welded constructions significantly affect the fatigue strength and stress corrosion crack resistance of the weld joint, and therefore, numerous studies have been made about the effects. Residual stresses induced by electron beam welding (EBW) have also been researched in various approaches; however, many of the research papers are associated with thick plates (with a thickness of $50 \mathrm{~mm}$ or more). ${ }^{1-5)}$ This was because the EBW process was costly and thus studied on cost-effective thick plate components for such specific applications as observed in the nuclear-power and space-related fields that required extremely high qualities for the weldments.

In recent years, however, there have been many cases where the EBW process is employed in such general applications as autos, electric machines, and industrial tools. This is owing to reduction in the processing cost through usage expansion of the equipment and job shop's corporate efforts. In particular, EBW is applied for partial penetration welding of parts with a plate thickness of $3-15 \mathrm{~mm}$ as observed in car gears and gauge diaphragms. While EBW has been expanded in sheet metal applications, there are little reports of in-depth research on this field. Taking this into consideration, the authors have researched the residual stress characteristics in the partial penetration EBW welds of sheet metals.

In the previous report, ${ }^{6)}$ the effects of beam power and

\footnotetext{
* Corresponding author: E-mail: nagai.takuya@kobelco.com DOI: http://dx.doi.org/10.2355/isijinternational.55.241
}

diameter were investigated in an orderly sequence for carbon steel (SS400). Consequently, it was clarified that the extent of the transverse residual stress at the weld toe, which largely affected the fatigue strength, related to the weld penetration. In the present report, the residual stress characteristics have been studied with varied types of metals. Specifically, the testing plates were made first with ferritic and martensitic structural steels (SS400, HT60, S50C, and SCM440) in the constant welding condition and were investigated for the residual stress characteristics by X-ray stress measurement and finite-element-method (FEM) analysis. Subsequently, the similar measurement and analysis were conducted with different types of materials (SUS304 and A5052) to compare and examine the effects of the type of metal on the residual stress in the partial-penetration sheetmetal weld by EBW.

In the present study, the testing plates are referred to as "sheet metal" in the EBW applications, in contrast to heavy thick metal having a thickness of $50 \mathrm{~mm}$ or thicker, which have conventionally been welded by EBW.

\section{Test Procedures}

\subsection{Testing Materials}

For the testing materials, ferritic and martensitic steels (SS400, HT60, S50C, and SCM440) plus, for comparison, austenitic stainless steel (SUS304) and aluminum alloy (A5052) were selected. The dimensions of each testing material were prepared to have $10-\mathrm{mm}$ thickness $\times 100-\mathrm{mm}$ width $\times 100$-mm length (Fig. 1). The plate thickness of $10 \mathrm{~mm}$ was selected in consideration of the common plate 


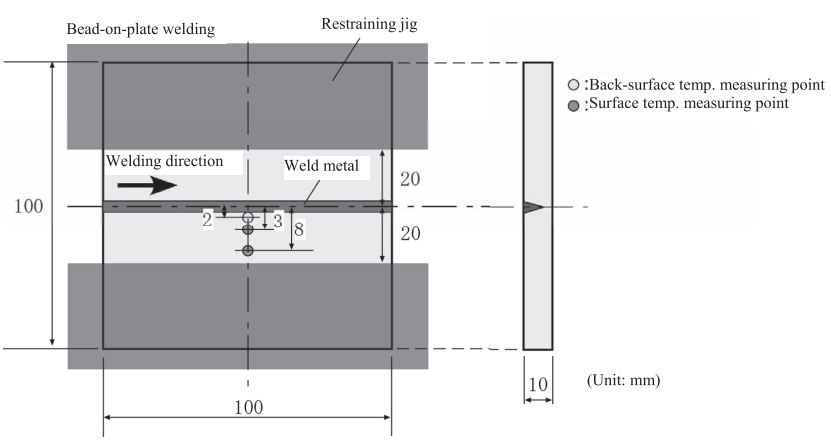

Fig. 1. Shape and dimensions of testing plate and temperature measuring points.

thickness range from several millimeters to ten-odd millimeters used in partial penetration welding by EBW.

\subsection{Welding Procedures}

Bead-on-plate welding was conducted by using a $6-\mathrm{kW}$ EBW machine made by Mitsubishi Electric Corp. (Fig. 2). The welding parameters were kept constant as shown in Table 1 for all types of metals in order to compare the effects of variations of metal types. The focal spot of the electron beam was set on the surface of the testing plate. The beam diameter referred to here was a theoretical value; i.e., the beam width at an intensity of up to $1 / \mathrm{e}$ (approx. $37 \%$ of the peak value) was used as the beam diameter.

Welding test was repeated twice in each condition. One test plate was restrained with a couple of restraining plates clamped at six points on the right and left sides of the testing plate. The restraining plates on the testing plate were removed in about three minutes from starting the test welding, taking into account the required time for opening the chamber to the atmosphere.

The restraining force was about $390 \mathrm{~N}$ measured by a load sensor at each clamping position. One restraining plate (with a $3000-\mathrm{mm}^{2}$ contacting area on the testing plate) was clamped at three locations, and thus the restraining stress could be calculated as $390 \mathrm{~N} \times 3 / 3000 \mathrm{~mm}^{2}=0.39 \mathrm{MPa}$.

In order to verify the testing plate was sufficiently restrained, the gap between the testing plate and the fixture was checked with a gap gauge $(0.05 \mathrm{~mm})$ before welding after restraining, and before releasing the restraint after welding; as a result, no gap was observed.

\subsection{Method of Measuring Temperature Transitions}

The surface temperature of the testing plates was measured to obtain temperature transitions during welding and to develop the basic data for determining the heat input conditions for the FEM analysis. The temperature was measured, as shown in Fig. 1, at $3 \mathrm{~mm}$ and $8 \mathrm{~mm}$ on the surface as well as $2 \mathrm{~mm}$ on the bottom respectively from the welding line. The temperature measurement was carried out for all the test plates, using a MEMORY HiCORDER 8423 made by Hioki E. E. Corp., together with glass-fiber-coated $\mathrm{K}$-thermocouples made of $0.32-\mathrm{mm} \Phi$ wires. The tip of the thermocouple was fixed on the measuring point in the testing plate by resistance welding, and the other end of the thermocouple was connected to the terminal block placed in the vacuum chamber. Another terminal block was placed outside the vacuum chamber and was connected to the ter-

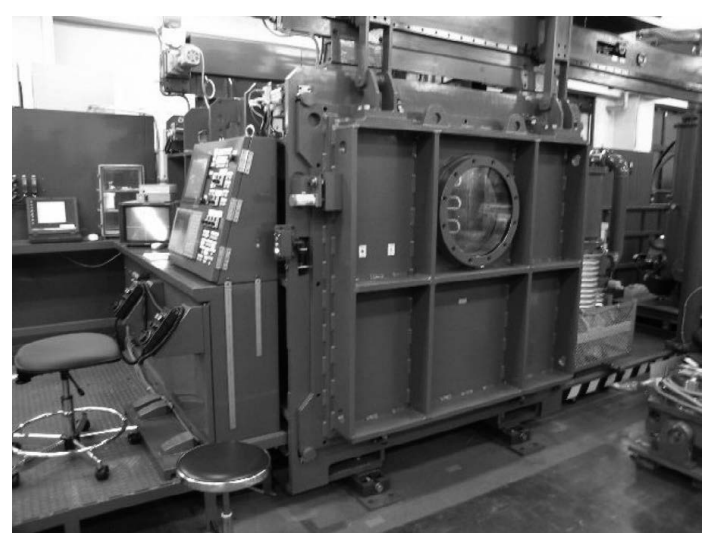

Fig. 2. Equipment for electron beam welding.

Table 1. Welding conditions.

\begin{tabular}{ccccccc}
\hline Test No. & 1 & 2 & 3 & 4 & 5 & 6 \\
\hline Type of metal & SS400 & S50C & HT60 & SCM440 & SUS304 & A5052 \\
\hline Beam power & & $1200 \mathrm{~W}$ & \\
Beam diameter & \multicolumn{5}{c}{$0.49 \mathrm{~mm}$} \\
Welding speed & \multicolumn{5}{c}{$500 \mathrm{~mm} / \mathrm{min}$} \\
\hline
\end{tabular}

minal block in the vacuum chamber; and thus, the electric signals from the thermocouples could be output outside the chamber. The terminal block set outside the chamber was wired to the MEMORY HiCORDER with a dedicated compensation wire for K-thermocouple. The measurement frequency was 10 plots per second. In order to reduce the power source noise during welding and the ambient noise, the built-in low-pass filter of the MEMORY HiCORDER was set at a cutoff frequency of $5 \mathrm{~Hz}$. Since the terminal blocks set inside and outside the chamber were connected with the different material wire from that for the thermocouple, there was a fear of measurement error due to the electromotive force generated at the terminal blocks. However, this kind of error was regarded as almost negligible because the measurement was carried out indoors and thus the ambient temperature difference between the two terminal blocks was minimal.

\subsection{Method of Measuring Residual Stresses}

For measuring residual stresses, X-ray diffraction method was used because the authors intended to measure the residual stresses in the surface area near the weld toe. For measuring the residual stresses, an X-ray stress analyzer made by Rigaku Corp was used. The measurement locations were 7 points at $0.5-6.5$ millimeters from the weld toe at $1.0 \mathrm{~mm}$ intervals as shown in Fig. 3. The diameter of the hole for measurement was $1.0 \mathrm{~mm} \Phi$. The measurement was carried out in the two directions of transverse $\left(\sigma_{\mathrm{T}}\right)$ and longitudinal $\left(\sigma_{\mathrm{L}}\right)$ with respect to the weld axis. The measuring surface was treated by electrochemical polishing (in a depth of approximately $100 \mu \mathrm{m}$ ) to eliminate the effect of the surface processing strain. In electrochemical polishing, the testing plate was set to be anode, and cathode was set against the surface to be polished with an electrolytic solution filled between them for metal elution. In order to measure residual stresses accurately, the electrochemically polished surface 
must be flat and smooth. In this research, the proper electrochemical polishing condition was established for each type of metal to ensure the flat measuring surfaces (Fig. 4). The method of measuring residual stresses basically complied with the Standard for X-ray Stress Measurement of the Society of Materials Science, Japan. ${ }^{7-9)}$ That is, the specimen was exposed to X-ray with several variations of incident angles for obtaining the diffraction angle $(2 \theta)$ of the diffraction X-ray, thereby observing a stress-induced variation in the lattice spacing. The measuring conditions are shown in Table 2.

The angle $\Psi$ is the angle between the normal line to the specimen surface and that to the diffraction surface, which corresponds to the incident angle of X-ray onto the specimen. The diffraction angle for each $\Psi$ degree was determined by the half-value breadth midpoint method, and the residual stress was calculated by multiplying the stress constant and the inclination of the $2 \theta-\sin ^{2} \Psi$ diagram.

\subsection{FEM Approach}

To verify the measurements of residual stress, FEM analysis software was used. For the analysis code, the welding heat analysis and simulation program, "Quick Welder," produced by the Research Center of Computational Mechanics, Inc. was used. Quick Welder is a program for conducting the thermal elasto-plasticity analysis with the addition of deposited metal and welding heat, which uses, similarly to general thermal elasto-plasticity analysis programs, the equation of the non-steady heat conduction and the equation based on the force balance formula associated with thermal expansion strain of a thermal elasto-plastic body.

For the analytical model, a three-dimension model with $20 \mathrm{~mm}$ in the longitudinal direction and right-left symmetric 1/2 part with respect to the weld axis, as shown in Fig. 5, was adopted in consideration of shortening the time of com-

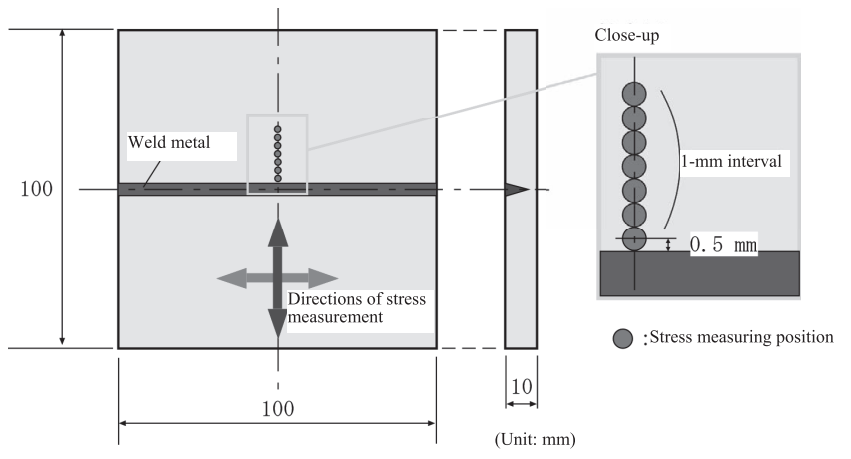

Fig. 3. Locations and directions of residual stress measurement.

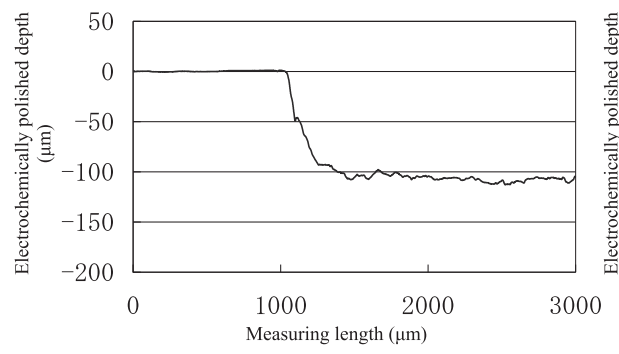

(a) Example of smoothly polished surface putation. Also, a model with $100 \mathrm{~mm}$ in the longitudinal direction, which was the same as the actual test specimen, was analyzed; as a result, it was revealed that there was no significant difference in the analytical results, including temperature and strain as compared with those of the model with the longitudinal size of $20-\mathrm{mm}$. This is probably because the mechanical melting zone in EBW is narrow unlike general arc welding, and thus the calculation results of the model with $20 \mathrm{~mm}$ in the longitudinal direction are not a lot different from the case of the model with the longitudinal size of $100 \mathrm{~mm}$. The restraining condition was set to be consistent with that in the actual welding; i.e., the same position was fully restrained in the $\mathrm{Z}$ direction (the direction of angular distortion) for 3 minutes after welding. The welding condition was set to be the same as that for the actual welding as shown in Table 1. Since the welding condition was kept constant for all types of steel, the influence of the

Table 2. X-ray stress measurement conditions.

\begin{tabular}{|c|c|c|c|}
\hline Type of metal & $\begin{array}{l}\text { SS400, S50C, } \\
\text { HT60, SCM440 }\end{array}$ & SUS304 & A5052 \\
\hline Measuring method & \multicolumn{3}{|c|}{$\Omega$-Diffractometer method } \\
\hline Characteristic X-ray & $\mathrm{Cr}-\mathrm{K} \alpha$ & $\mathrm{Cr}-\mathrm{K} \beta$ & $\mathrm{Cr}-\mathrm{K} \alpha$ \\
\hline Tube voltage & \multicolumn{3}{|c|}{$30 \mathrm{kV}$} \\
\hline Tube current & \multicolumn{3}{|c|}{$10 \mathrm{~mA}$} \\
\hline Diffractive plane & $(211)$ & \multicolumn{2}{|c|}{$(311)$} \\
\hline Diffractive angle, $2 \theta$ & $156.4^{\circ}$ & $148.5^{\circ}$ & $139.3^{\circ}$ \\
\hline Angle of $\psi$ & \multicolumn{3}{|c|}{11 angles between $0-45^{\circ}$} \\
\hline Oscillation angle of $\psi$ & \multicolumn{3}{|c|}{ $\pm 3^{\circ}$} \\
\hline Stress constant & $-318 \mathrm{MPa} / \mathrm{deg}$ & $-366 \mathrm{MPa} / \mathrm{deg}$. & $-166 \mathrm{MPa} / \mathrm{deg}$. \\
\hline $\mathrm{X}$-ray exposure time & $120 \mathrm{sec} / \psi$ & \multicolumn{2}{|c|}{$300 \mathrm{sec} / \psi$} \\
\hline $\mathrm{X}$-ray exposure area & \multicolumn{3}{|c|}{$1 \mathrm{~mm} \Phi$} \\
\hline
\end{tabular}

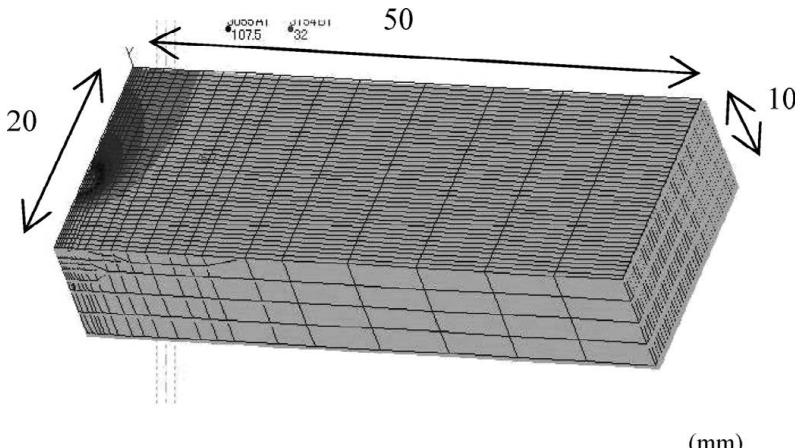

Fig. 5. Analytical model.

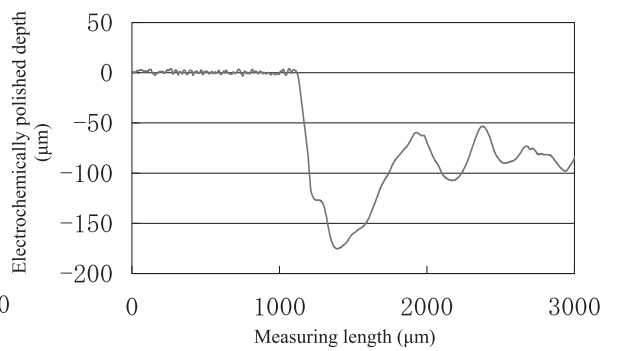

(b) Example of roughly polished surface

Fig. 4. Conditions of electrochemically polished surfaces (SS400). 
type of steel could be clarified. Other analytical conditions were those shown in Table 3. The physical properties used associated with temperature dependency were those given in Fig. 6 for example; whereas, density and Poisson's ratio were kept constant regardless of temperature dependency.

\section{Experimental Results and Discussions}

\subsection{Comparison between Temperature Measurements and FEM Analysis Results}

Cross-sectional macrographs of welds are shown in Fig.

Table 3. Analysis conditions.

\begin{tabular}{c|c|c}
\hline \multirow{2}{*}{$\begin{array}{c}\text { Boundary } \\
\text { condition }\end{array}$} & Atmosphere (Vacuum) & $\begin{array}{c}\text { Radiant heat transfer at } \\
\text { an emissivity of } 0.2\end{array}$ \\
\cline { 2 - 3 } & Restraint & $\begin{array}{c}\text { Restrained at the same location } \\
\text { for the same time as taken } \\
\text { in the welding test }\end{array}$ \\
\cline { 2 - 3 } Heat source & Internal calorific type $\left(\mathrm{W} / \mathrm{m}^{2} \cdot \mathrm{K}\right)$ & $\begin{array}{c}3489 \text { as heat transfer coefficient } \\
\text { Heat source is input into } \\
\text { the penetration area defined } \\
\text { with cross-sectional macrograph }\end{array}$ \\
\hline \multicolumn{2}{c}{ Efficiency of heat input } & $70-80 \%$ \\
\hline \multicolumn{2}{c}{ Number of elements } & Approx. 15000 \\
\hline
\end{tabular}

7. Since the welding condition was kept constant, penetration depth and bead width resulted in similar measurements for all the testing materials (Table 4). The FEM analysis model was made based on these macrographs. Figure 8

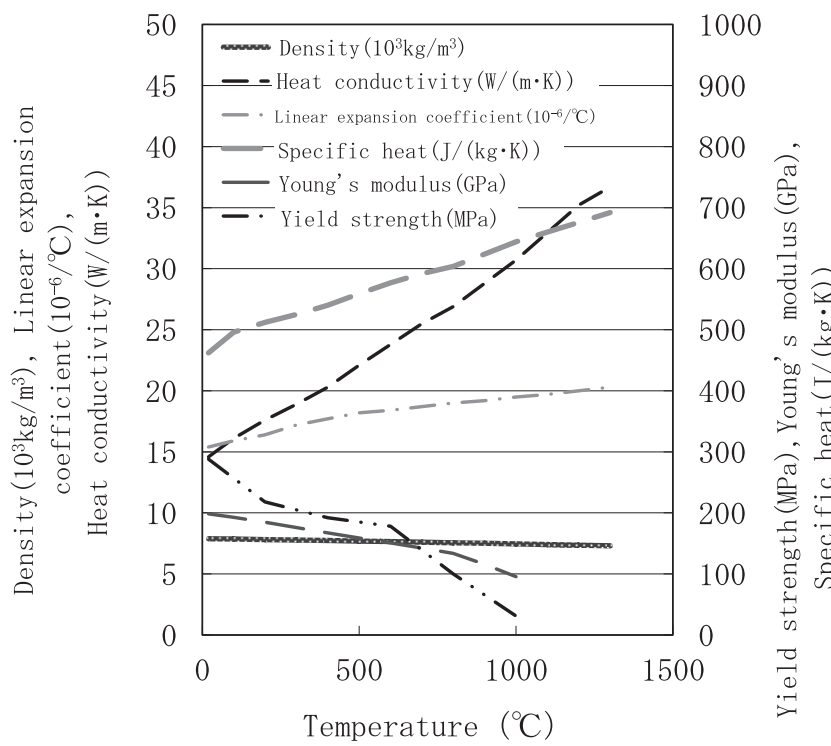

Fig. 6. Example of physical properties (SUS304).

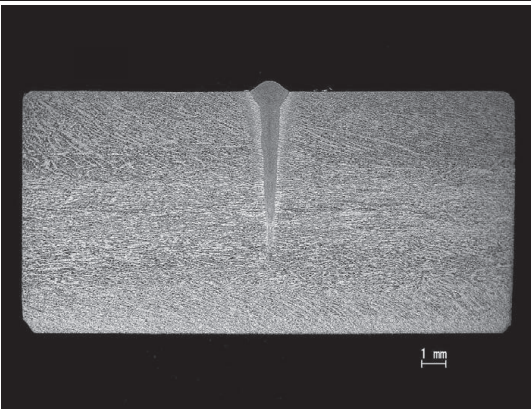

(a) $\operatorname{SS} 400$

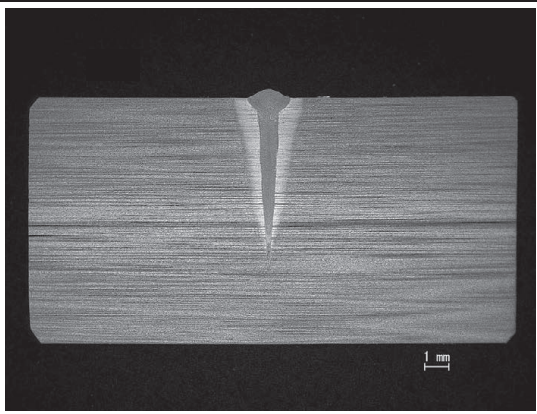

(c) HT60

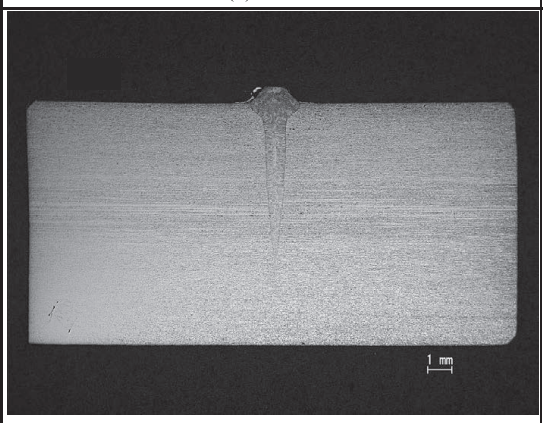

(e) SUS304

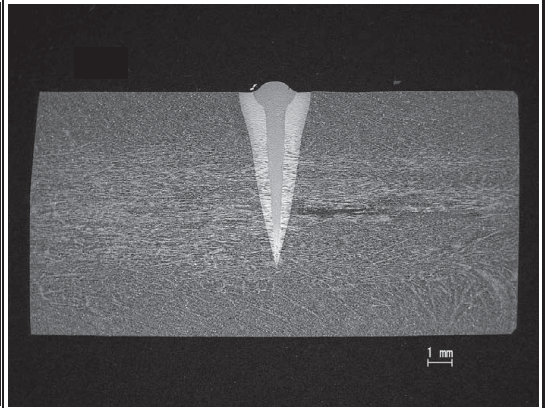

(b) $\mathrm{S} 50 \mathrm{C}$

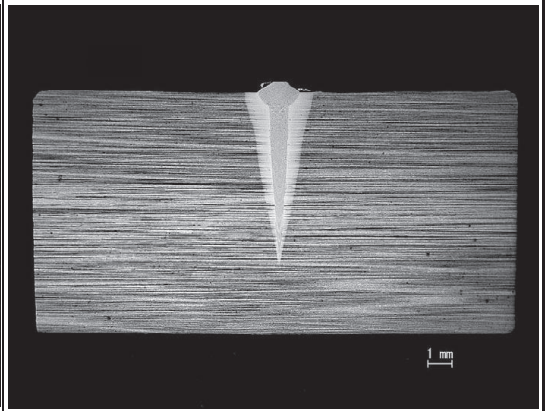

(d) SCM440

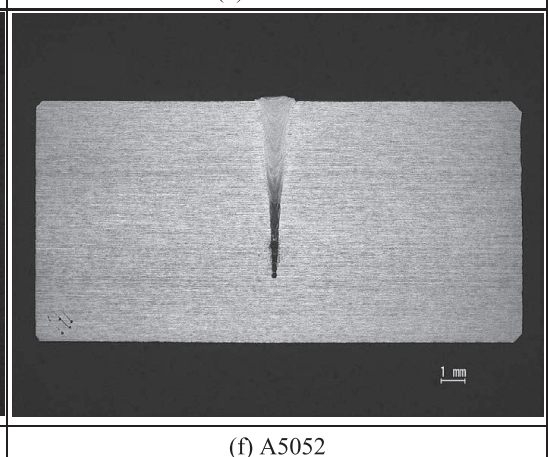

(f) A5052

Fig. 7. Cross-sectional macrographs of welds. 
shows the temperature transitions obtained by measurement and analysis during welding of each testing material. FEM analysis was carried out with appropriate analytical conditions; consequently, the analysis results exhibited relatively good agreement with the temperature measurements. In cases where the heat transfer must be adjusted in the analytical model, it is essentially preferable to have an actual measurement area that reaches around $800^{\circ} \mathrm{C}$; whereas, the actual measurement temperature in this experiment was about $300^{\circ} \mathrm{C}$ maximum for all the testing steel plates. It was tried to position the thermocouples closer to the weld bead (Fig. 9); however, the most appropriate locations were judged to

Table 4. Measurements of weld metal dimensions.

\begin{tabular}{ccccccc}
\hline Test No. & 1 & 2 & 3 & 4 & 5 & 6 \\
\hline Type of metal & SS400 & S50C & HT60 & SCM440 & SUS304 & A5052 \\
\hline Penetration depth (mm) & 7.0 & 7.0 & 7.1 & 6.8 & 7.4 & 7.3 \\
Bead width (mm) & 1.6 & 1.8 & 1.8 & 1.8 & 2.1 & 1.8 \\
\hline
\end{tabular}

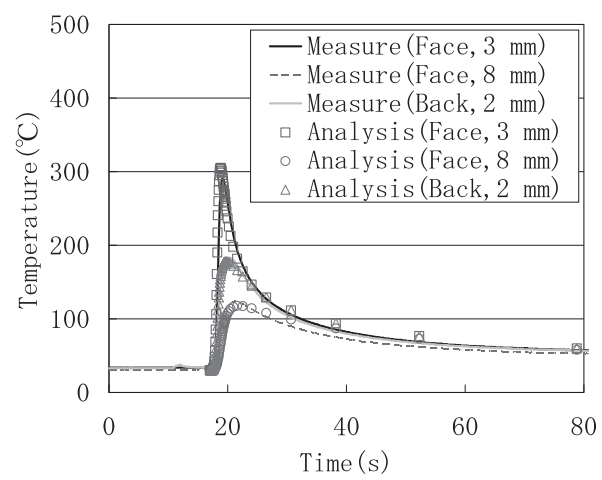

(a) $\mathrm{SS} 400$

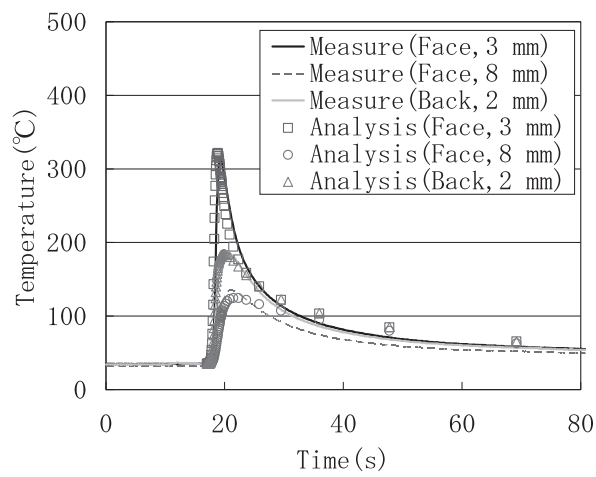

(c) HT60

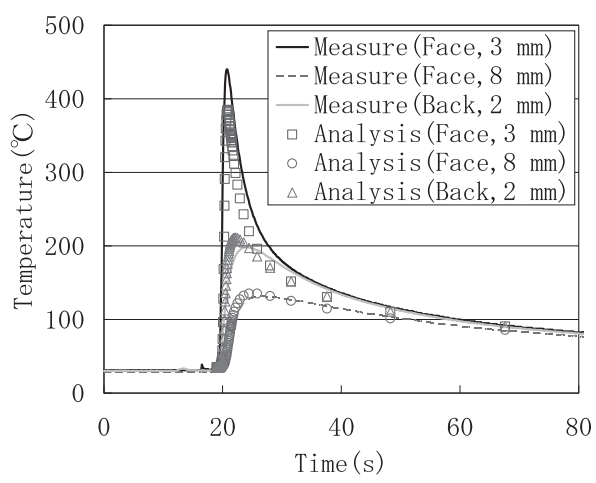

(e) SUS304 be 3 and $8 \mathrm{~mm}$ on the surface and $2 \mathrm{~mm}$ on the backside surface to prevent the weld bead from meandering affected by the thermocouple's glass covering. With these measuring points, the appropriate measurement was conducted without

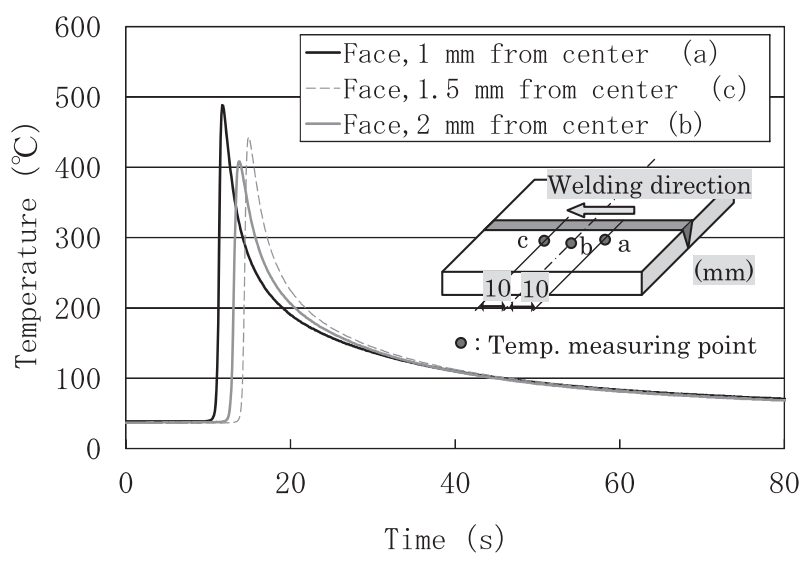

Fig. 9. Temperature transition vs. thermocouple's position.

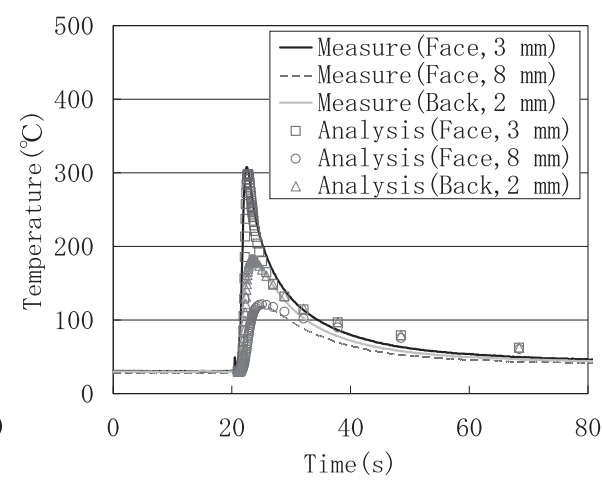

(b) $\mathrm{S} 50 \mathrm{C}$

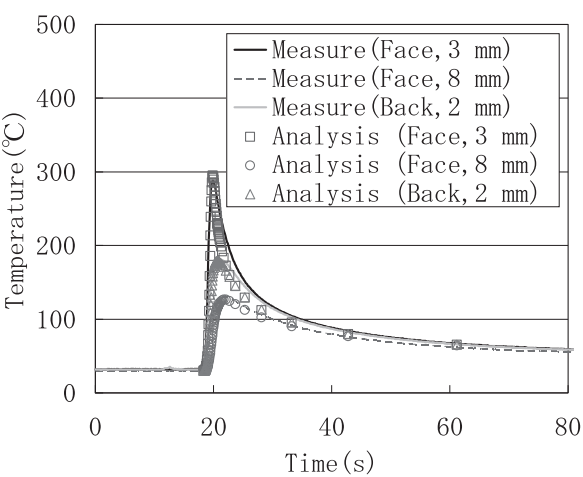

(d) SCM440

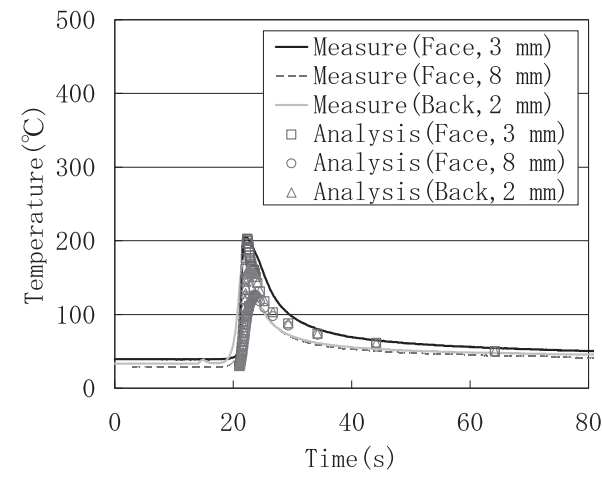

(f) A5052

Fig. 8. Comparison of temperature transitions between measurement and analysis. 
a breakage of thermocouple for all the testing steel plates, though the maximum temperature was lower.

\subsection{Comparison between Residual Stress Measure- ments and FEM Analysis Results}

Figure 10 shows the transverse residual stresses $\left(\sigma_{\mathrm{T}}\right)$, and Fig. 11 shows the longitudinal residual stresses $\left(\sigma_{\mathrm{L}}\right)$. For the transverse residual stresses, the tendencies of measurement and analysis data are consistent with each other. Compressive residual stresses are observed near the weld toe, and they become zero as the measuring point departs from the weld toe. Similarly, for the longitudinal residual stresses, the measurement and analysis data are consistent with each other. The longitudinal residual stresses exhibit peak values of tension near the weld toe, and they gradually reduce as the measurement and analysis points depart from the weld toe. For the experimental measurements and analytical values shown in the correlation diagrams in Fig. 12, the data in the transverse direction clearly coincide with each other, and similarly the data in the longitudinal direction roughly correlate each other though some variations are observed. In terms of correlation coefficient, obtained were 0.935 for $\sigma_{\mathrm{T}}$ and 0.609 for $\sigma_{\mathrm{L}}$ with the rejection region of 0.479 at a $99 \%$ confidence interval; thus, the correlation can be recognized. On the other hand, there is a comparatively large difference especially near the weld toe in both the longitudinal and transverse directions; this is probably because the stress inclination at the area near the weld toe is larger. This is also because the residual stress obtained by analysis is the value of a particular point whereas that obtained by measurement

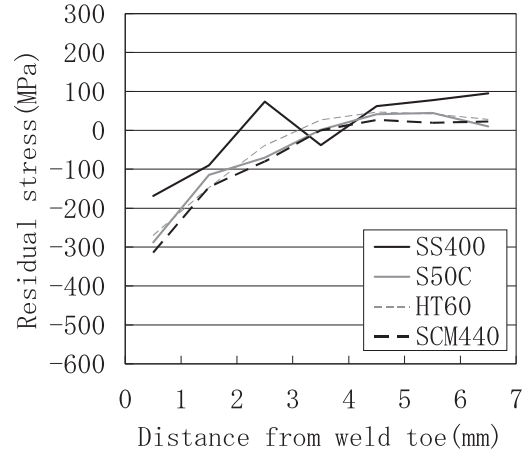

(a) Measurement results

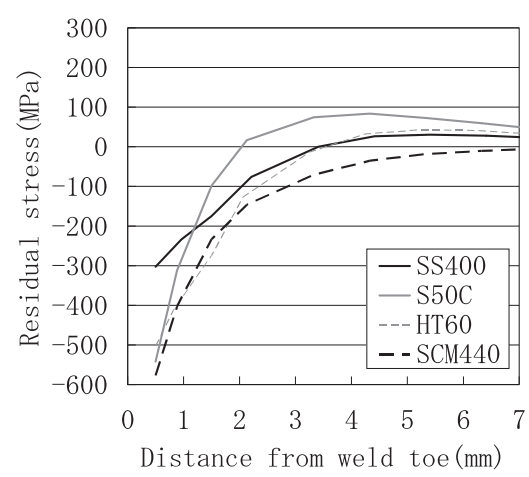

(b) Analysis results

Fig. 10. Transverse residual stress $\left(\sigma_{\mathrm{T}}\right)$.

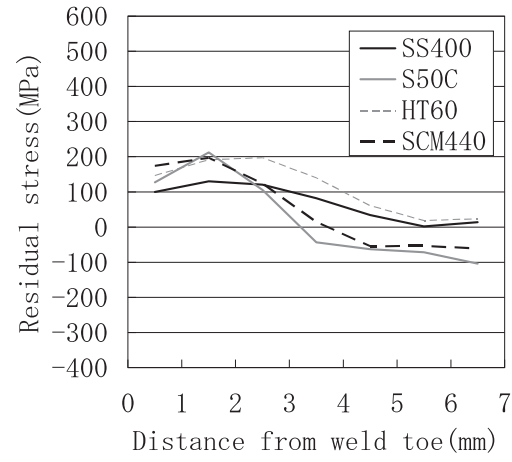

(a) Measurement results

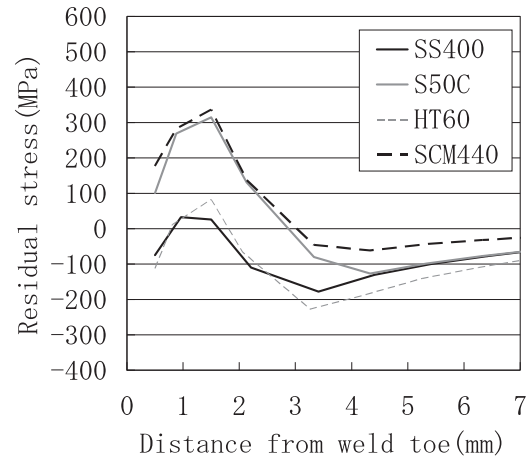

(b) Analysis results

Fig. 11. Longitudinal residual stress $\left(\sigma_{\mathrm{L}}\right)$.

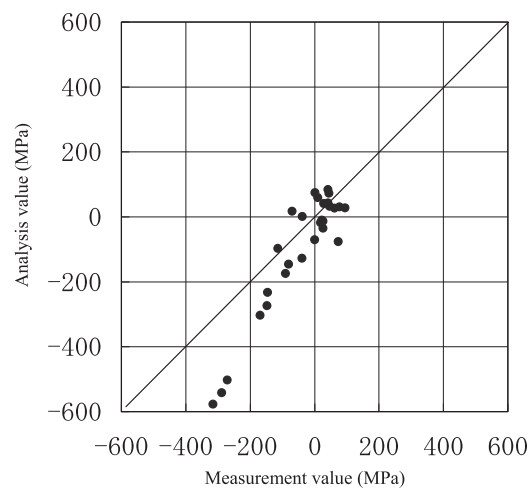

(a) Transverse direction $\left(\sigma_{\mathrm{T}}\right.$

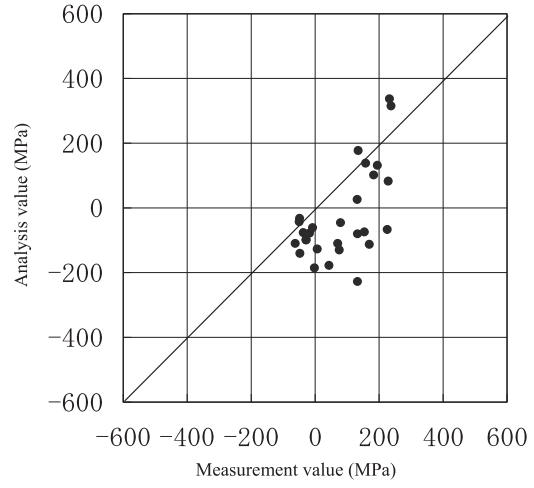

(b) Longitudinal direction $\left(\sigma_{\mathrm{L}}\right.$

Fig. 12. Correlation diagram of residual stresses by measurement and analysis. 
is the average value of the X-ray irradiated area of $1 \mathrm{~mm} \Phi$. Good agreement can be observed in the part where the inclination is smaller. From the above facts, the analytical results can be deemed usable. Since the residual stress near the weld toe is more important and the heat conduction of the analytical model almost agrees with that of the measurement, the residual stress in the vicinity of the weld toe will be discussed below based on the analytical results.

\subsubsection{Transverse Residual Stress $\left(\sigma_{\mathrm{T}}\right)$}

As shown in Fig. 10, the surface residual stresses $\left(\sigma_{\mathrm{T}}\right)$ in the transverse direction are compression stresses in the area near the weld toe and tend to shift toward the tension stress side reaching zero as the testing point departs from the weld toe for all the testing steel plates. Figure 13 shows crosssectional views of the analytical model, which exhibits residual stress distributions for each type of steel. There can clearly be observed the distributions of compression stress in the steel surface area and of maximal tension stress in the vicinity of the plate thickness-wise center. This agrees with the already reported experimental results. $\left.{ }^{6}\right)$ This also has a good matching to such findings, reported for some past researches on the complete penetration weld of thick plate, that compression stress generated in the plate surface and tension stress at the midpoint of the plate thickness. ${ }^{1,2,10)}$ The residual stress distributions described above are unique to EBW joints. $\left.{ }^{6}\right)$ The reason for such a specific stress distribution is that the EBW process uses an electron beam of extremely high energy-density to form a weld in a very narrow zone, unlike multiple pass welding by a general arc welding process. The bead surface tends to be rapidly heated and cooled; therefore, when the high-temperature portion is cooled down to around the mechanical melting point, the maximum temperature zone will still exist around the midpoint of the plate thickness. This is presumably why the area around the midpoint of the plate thickness is cooled slower than the bead surface area, thereby generating tension stresses associated with delayed shrinkage. Also, in the weld surface area, compression stresses can be considered to generate to

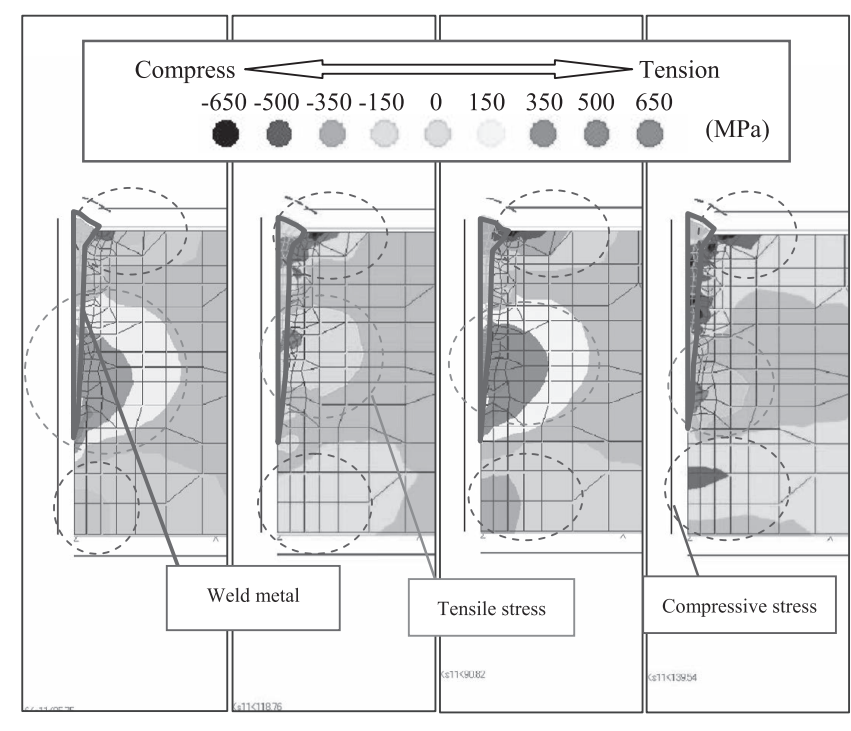
(a) SS400
(b) $\mathrm{S} 50 \mathrm{C}$
(c) HT60
(d) SCM440

Fig. 13. Cross-sectional distributions of transverse stresses $\left(\sigma_{\mathrm{T}}\right)$. balance the tension stresses. For the data that supports this mechanism, the temperature transitions measured in the plate thickness-wise center are shown in Fig. 14. For measuring the temperature in the plate thickness-wise center, a sheathed thermocouple was used. This figure shows how the maximum temperature area is moved affected by the thermal transport from the surface to the vicinity of the plate thickness-wise center. However, as discussed in Section 3.1, the measurable temperature range was $500^{\circ} \mathrm{C}$ maximum.

\subsubsection{Longitudinal Residual Stress $\left(\sigma_{\mathrm{L}}\right)$}

The longitudinal stresses in the plate surface area exhibited maximal values near the weld toe for every steel plate, and they tended to decrease gradually reaching zero as the testing point departed from the toe. In general arc welding, it is known that the entire longitudinal length along the weld axis is highly heated and rapidly cooled, thus the mechanical restraining condition becomes severe, thereby generating the tensile stress equivalent to the yield strength level in the weld metal and heat-affected zone. ${ }^{11)}$ By contrast, in EBW, the tensile residual stress was not as large as that level. This is probably because the heat input in EBW is lower, and the melting zone is narrower as compared to those in arc welding, and thus the mechanical restraint against the weld metal along the weld axis is less than in arc welding. In the weld toe areas of S50C and SCM440 whose room-temperature yield strength are as high as $500 \mathrm{MPa}$ or more, the residual stresses are of tensile, which are presumed to be generated in the weld metal cooling process. With lower yield strength materials of SS400, SUS304 and HT60, the residual stresses resulted in the values near $0 \mathrm{MPa}$. This can probably be attributed to the compression stress in the plate surface area, similarly to the mechanism discussed on the transverse residual stress.

\subsubsection{Effect of the Type of Steel on Residual Stress}

Since the welding condition was kept constant, penetration depth and bead width resulted in the similar dimensions for all the testing steel plates; therefore, the difference in residual stress can be deemed to be the effect of the type of steel. As shown in Fig. 15, it has been found that the residual stress at the weld toe correlates with the room-temperature yield strength of each type of steel. In the longitudinal direction, the residual stress becomes tensile to a larger extent as

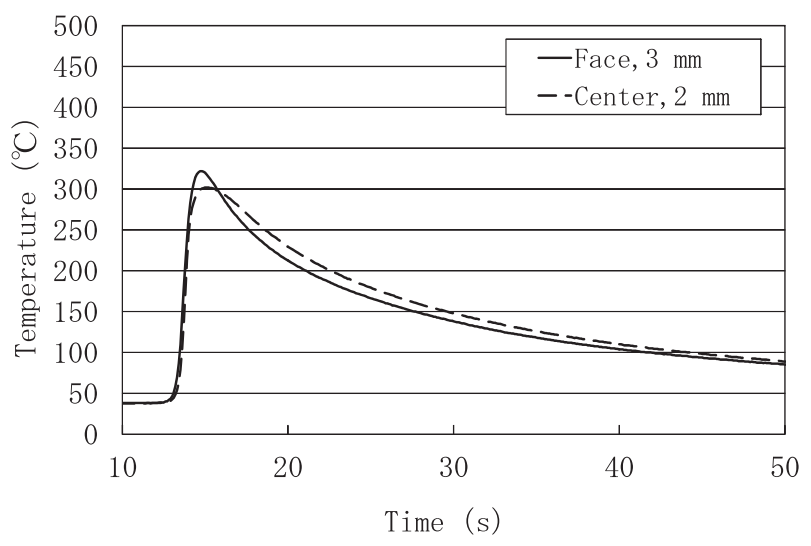

Fig. 14. Comparison of temperature transitions in surface and interior (Measurement). 
the yield strength of the testing steel material is higher. This is the same tendency as observed in general arc welding. In the transverse direction, the residual stress becomes compression to a larger extent as the yield strength of the testing steel material is higher. To explain the dependency of yield strength on the transverse residual stress, the effect of addition of the compression stress induced by the transformation expansion of the weld was first taken into consideration. Figure 16 shows the analysis result with or without consideration of transformation. From this figure, it can be said that almost no difference is observed in the residual stresses with or without the consideration of transformation; i.e., the effect of transformation is not significant. In the already reported research, ${ }^{6}$ the authors investigated the effects of welding conditions and clarified that the residual stress at the weld toe became compression as the result of the reaction of internal tensile stress at a greater extent proportional

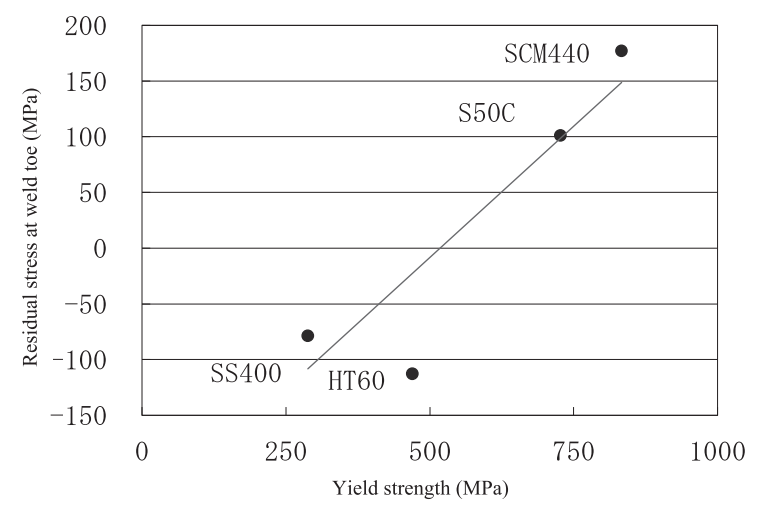

(a) Longitudinal direction $\left(\sigma_{\mathrm{L}}\right)$

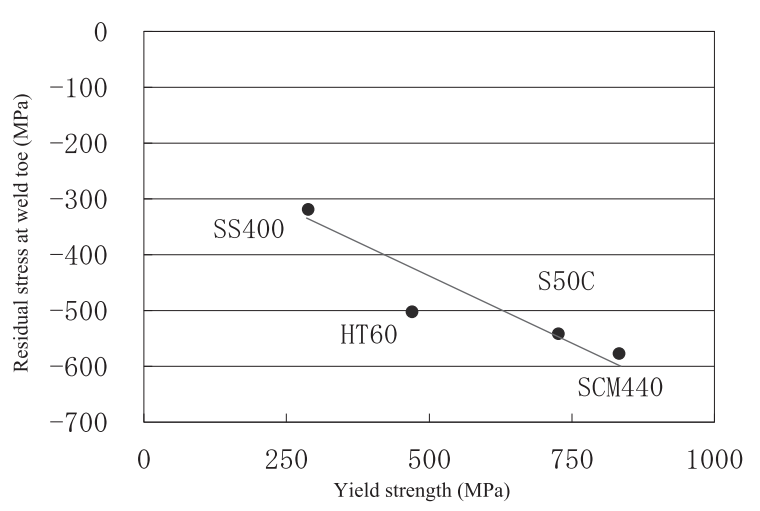

(b) Transverse direction $\left(\sigma_{\mathrm{T}}\right)$

Fig. 15. Residual stress at weld toe vs. yield strength.

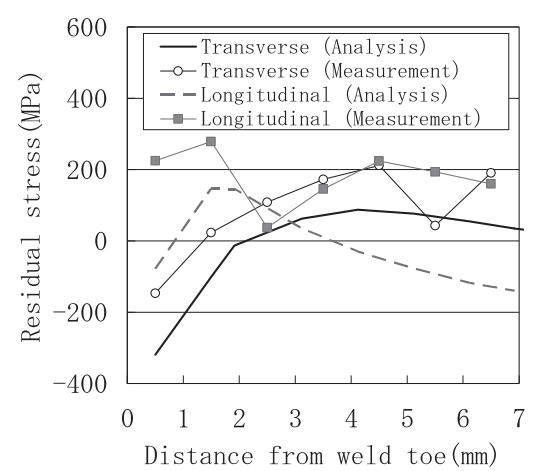

(a) SUS304 to penetration depth. In the present study, penetration depths were almost the same for all the testing steel plates. Taking into account the fact that the longitudinal residual stress becomes tensile to a greater extent as the yield strength of the testing steel material increases, the mechanism of the behavior of the transverse residual stress at the weld toe can be assumed in such a way that, in EBW with a narrow bead width, the transverse residual stress near the weld toe that impacts the fatigue strength is affected remarkably by the compression stress corresponding to the Poisson's ratio associated with the longitudinal tensile residual stress.

\subsection{Residual Stress Characteristics of Supplementary Materials}

For comparison with ferritic and martensitic steels (SS400, HT60, S50C, and SCM440), the supplementary materials of austenitic stainless steel (SUS304) and aluminum alloy (A5052) were researched on their behavior in the residual stress. Figures 17(a) and 17(b) show the results of SUS304 and A5052, respectively. As to the results of SUS304, some points exhibit considerable differences between measurement and analysis. The considerable variability of the measurement data at many testing points can probably be attributed to the effects of coarse crystalline grain and texture because the confidence limit of experimental measurements was as large as $\pm 50 \mathrm{MPa}$ or more. As to the results of A5052, the measurement and analysis values almost coincide. In comparison of the analysis values between SUS304 and A5052, the transverse residual stress tends to shift toward compression to a larger extent than the

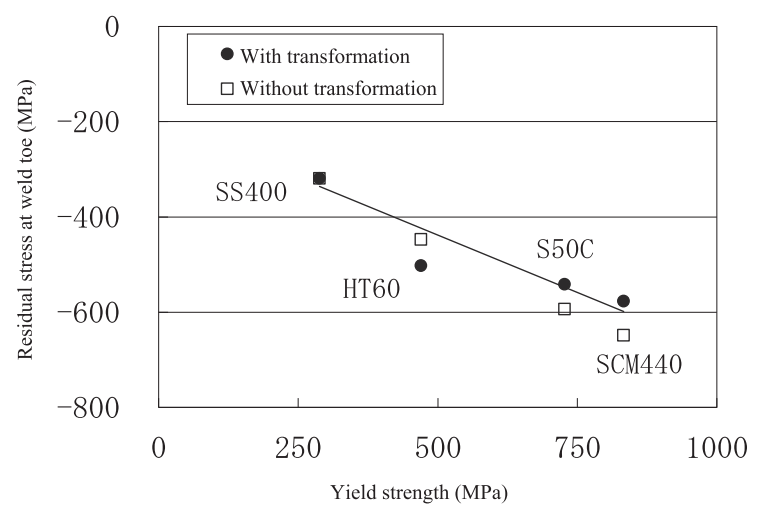

Fig. 16. Analysis results with or without consideration of transformation (Transverse residual stress at weld toe $\left(\sigma_{\mathrm{T}}\right)$ ).

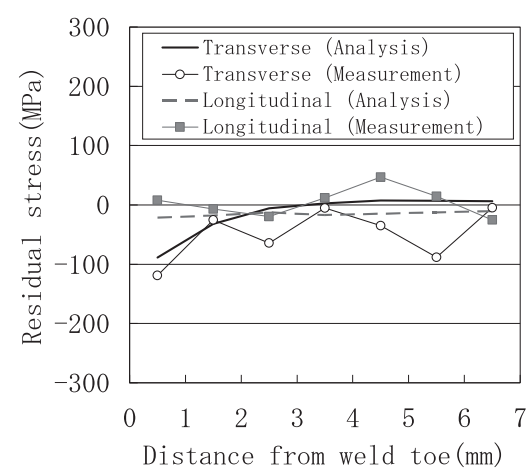

(b) A5052

Fig. 17. Measured and analyzed residual stresses of supplementary materials. 


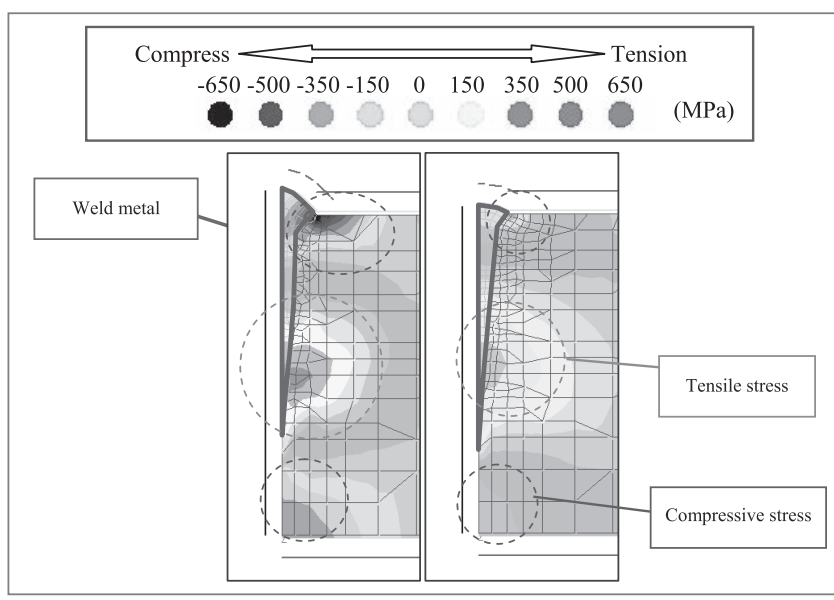

(a) SUS304

(b) A5052

Fig. 18. Cross-sectional distributions of transverse residual stresses $\left(\sigma_{\mathrm{T}}\right)$ of supplementary materials.

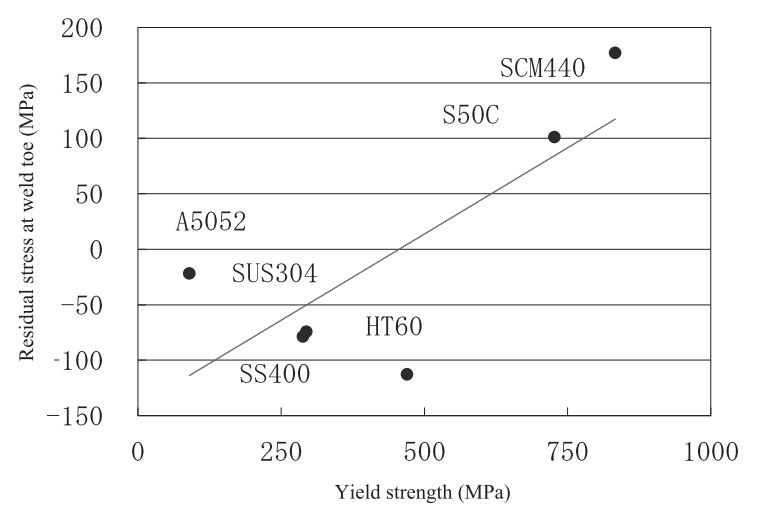

(a) Longitudinal direction $\left(\sigma_{\mathrm{L}}\right)$

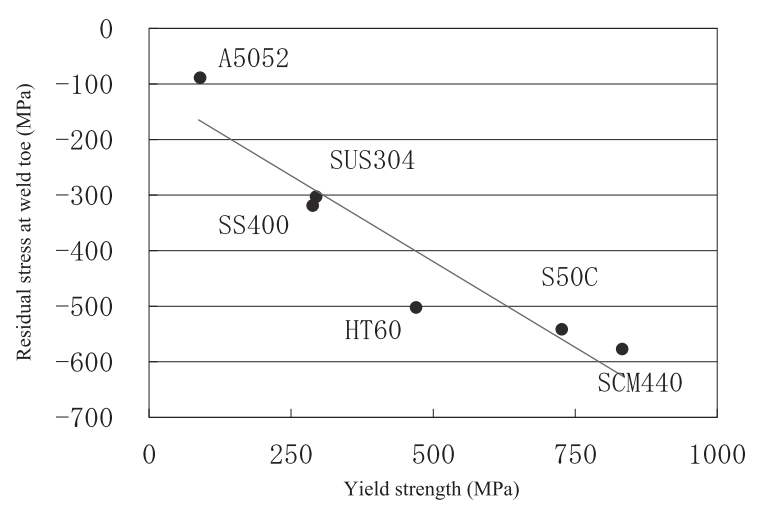

(b) Transverse direction $\left(\sigma_{\mathrm{T}}\right)$

Fig. 19. Yield strength vs. residual stress at weld toe (SUS304 and A5052 are added).

longitudinal residual stress at the weld toe. This tendency is consistent with the aforementioned results of SS400, HT60, S50C, and SCM440. Moreover, as shown in the transverse residual stress distributions in the weld cross sections in Fig. 18, the compression stresses are generated in the plate surface and backside surface areas, and the tension residual stresses occurred in the plate thickness-wise center. This residual stress distribution pattern is the same as that with the test materials of ferritic and martensitic steel. Figure 19 shows the residual stress at the weld toe as a function of yield strength, which includes the data of SUS304 and A5052 plotted in the residual stress vs. yield strength dia- gram previously obtained with the ferritic and martensitic steel materials. In the expanded category of the testing materials over the ferritic and martensitic steel, the following tendency can be observed. In the longitudinal direction, the residual stress becomes tensile to a larger extent as the yield strength of the testing material is higher, and in the transverse direction, the residual stress becomes compression to a larger extent as the yield strength of the testing material is higher.

\section{Conclusions}

Partial penetration thin-plate weldments were made by the EBW process to measure residual stresses and to verify the data by means of FEM analysis; consequently, the following conclusions have been obtained.

(1) The residual stresses in the surface areas showed a good agreement between the experimental measurements by the X-ray diffraction and the FEM analysis values. However, for the results of SUS304, the variability of the measurements was considerable.

(2) It has been found that the transverse residual stresses near the weld toe, which significantly affects fatigue strength, are of compression for all the testing materials, including four types or steel (SS400, HT60, S50C, and SCM440) and supplementary materials (SUS304 and A5052). It has also been clarified that the residual stress distribution in the cross section is of compression in the plate surface and backside surface areas and of tension in the interior of the plate for all the testing materials.

(3) In the longitudinal direction, the residual stress at the weld toe becomes tensile to a larger extent as the yield strength of the testing steel material is higher. By contrast, in the transverse direction, the residual stress becomes compression to a larger extent as the yield strength of the testing steel material is higher. This tendency can be observed not only for ferritic and martensitic steel materials but also for other types of metals such as SUS304 and A5052.

(4) The reason for the transverse residual stress to become compression to a larger extent as the yield strength of the testing steel material increases can probably be attributed to the significant effect of the compression stress corresponding to the Poisson's ratio associated with the longitudinal tensile residual stress.

\section{REFERENCES}

1) K. Oguiso: Proc. Symp. on X-Ray Studies on Mechanical Behaviour of Materials, Vol. 41, The Society of Materials Science, Kyoto, (2004), 12.

2) Y. Ueda, Y. C. Kim and A. Umekuni: O. J. Jpn. Weld. Soc., 4 (1986), 138.

3) M. Belassel, M. Brauss and J. Pineault: ASME PVP, 429 (2001), 9.

4) Y. Arai, M. Kikuchi, T. Watanabe and M. Nakagaki: Int. J. Pres. Ves. Pip., 63 (1995), 237.

5) S. Yamamoto, M. Takanashi and K. Iida: J. High Press. Inst. Jpn., 31 (1993), 74.

6) T. Suga, R. Kasai, T. Nagai, K. Ueno, M. Shindo and M. Mochizuki: O. J. Jpn. Weld. Soc., 30 (2012), 262.

7) D. Radaj: Welding Residual Stresses and Distortion, DVS-Verlag, Düsseldorf, (2003), 332.

8) J. Lu: Handbook of Measurement of Residual Stresses, The Fairmont Press, Inc., Lilburn, (1996), 49.

9) The Society of Materials Science: JapanStandard Method for X-Ray Stress Measurement, The Society of Materials Science, Kyoto, (2005), 5.

10) K. Nakacho, H. Murakawa and T. Koide: Report of the Research Center for Ultra-High Energy-Density Heat Source, Vol. 14, Joining and Welding Research Institute, Osaka University, Osaka, (1998), 34.

11) K. Satoh and T. Terasaki: J. Jpn. Weld. Soc., 45 (1976), 560. 